\title{
A study of urolithiasis in children admitted to a tertiary care hospital
}

\author{
Suneel Mundkur ${ }^{1}$, Satish Vemunuri ${ }^{1}$, Pushpa Kini ${ }^{1}$, Shrikiran A Hebbar ${ }^{1}$, ${ }^{*}$ Sowmya Shashidhara ${ }^{1}$, Nalini \\ Bhaskarananda ${ }^{1}$
}

Sri Lanka Journal of Child Health, 2019; 48(1): 33-38

\begin{abstract}
Background: Paediatric urolithiasis is now commoner and is associated with a high risk of recurrence and an increased morbidity.
\end{abstract}

Objectives: To study the clinical profile, the metabolic and anatomical risk factors predisposing to urolithiasis in children admitted to a tertiary care hospital.

Method: The study included children between 1 month and 18 years of age admitted in tertiary care with a diagnosis of urolithiasis. A detailed history, including demographic data, physical examination, laboratory parameters, imaging studies, 24 hour urine for metabolic workup were noted, Stone was sent for analysis of composition. The study period was from 2012 to 2017.

Results: The study group consisted of 56 children with a median age at onset of symptoms of 8.1 years. The common presenting symptoms were abdominal pain $(87.5 \%)$ and fever (30.4\%). Anatomical defects were associated with urolithiasis in $9(16.1 \%)$ children. Hypocitraturia was observed in $34(63.1 \%)$ children followed by hyperoxaluria in $20(37 \%)$ children. Hypercalciuria was observed in $8(14.8 \%)$ children. Majority $(71.5 \%)$ of calculi were in the kidney and were constituted by calcium oxalate $(75 \%)$. At follow up, $10(22.2 \%)$ children had persisting calculi, 7 $(15.5 \%)$ had a recurrence and in the remaining 28 $(62.2 \%)$ children no recurrence was observed.

Conclusions: Abdominal pain was the presenting symptom in $87.5 \%$ cases. Hypocitraturia was observed in $63.1 \%$ cases. Majority $(71.5 \%)$ of calculi were in the kidney. There were recurrent calculi in $15.5 \%$.

DOI: http://dx.doi.org/10.4038/sljch.v48i1.8649

\footnotetext{
${ }^{1}$ Kasturba Medical College, Manipal Academy of Higher Education, India

*Correspondence: sowmyashashidhara86@gmail.com (Received on 14 May 2018: Accepted after revision on 29 June 2018)

The authors declare that there are no conflicts of interest

Personal funding was used for the project.
}

Open Access Article published under the Creative

Commons Attribution CC-BY (c) (i) License
(Key words: Urolithiasis, abdominal pain, haematuria, hypocitraturia)

\section{Introduction}

Paediatric urolithiasis is now commoner and is associated with a high risk of recurrence and an increased morbidity ${ }^{1-3}$. Although in North India about $15 \%$ people are known to suffer from kidney stones, in southern India, incidence of renal calculi is less ${ }^{4}$. Most children diagnosed with calculi have underlying metabolic abnormalities. To prevent recurrence, identification of the metabolic abnormality enables both pharmacological and non-pharmacological interventions ${ }^{5}$.

\section{Method}

Study population and design

This observational study was conducted in Kasturba Medical College, Manipal, Karnataka, a tertiary care centre. All children aged 1 month to 18 years, admitted from August 2012 to July 2017 with urolithiasis were included in the study. Since this was a descriptive study, the sampling was done by including all children with urolithiasis. The study was approved by the Institutional Ethics Committee.

Data on detailed history including demographic data, physical examination, routine haematological and urine examination, metabolic evaluation with serum calcium, phosphorus and uric acid, imaging studies and 24 hour urine for metabolic evaluation were recorded, Stone composition and various modalities of treatment (medical and surgical) were also noted.

\section{Statistical evaluation}

This was done using IBM Statistical Package for Social Sciences (SPSS) statistics 21 software. Descriptive data were expressed as percentage, median and interquartile range.

\section{Results}

The total number of children admitted to the Department of Paediatrics during the study period fulfilling the inclusion criteria was 60. Four children were excluded from the study as the urine metabolic workup was not done. In the study group, out of 56 children, data of 38 children were collected retrospectively, and 18 children were recruited prospectively. The total number of children included in the present study was 56 (Figure 1). 


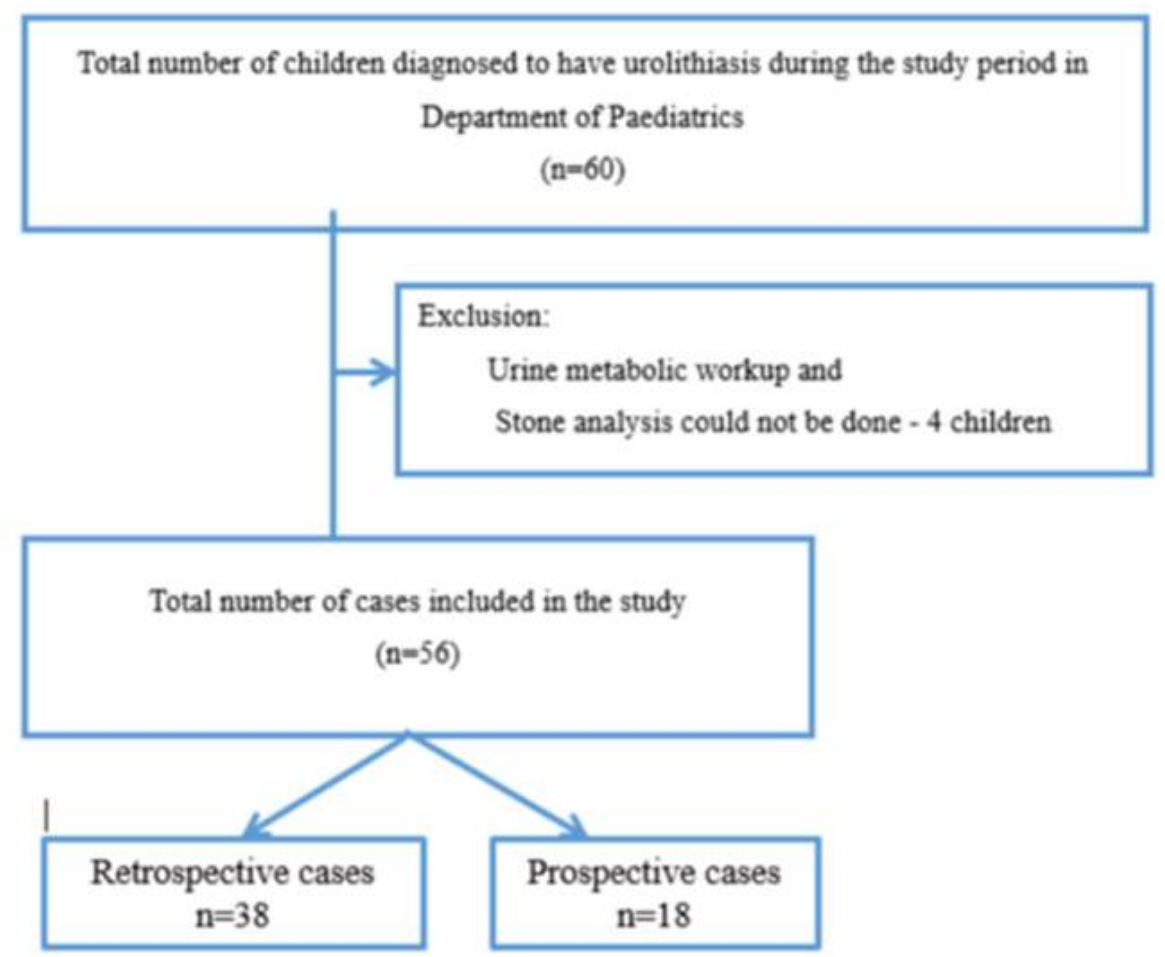

Figure 1: Flow diagram of the study population

The clinical profile of children with urolithiasis are shown in Table 1.

Table 1

Clinical profile of children with urolithiasis $(n=56)$

\begin{tabular}{|l|c|}
\hline \multicolumn{1}{|c|}{ Variable } & Number (\%) \\
\hline Age & $18(32.1)$ \\
1 month-5 years & $16(28.6)$ \\
$5-10$ years & $22(39.3)$ \\
$>10$ years & \\
\hline Gender & $38(67.9)$ \\
Male & $18(33.1)$ \\
Female & \\
\hline Complaints initial & $49(87.5)$ \\
presentation & $17(30.4)$ \\
Abdominal pain & $17(30.4)$ \\
Fever & $15(26.8)$ \\
Haematuria & $05(08.9)$ \\
Burning micturition & \\
Passage of stone & \\
\hline Systemic findings & $22(39.3)$ \\
Malnutrition & $06(10.7)$ \\
Overweight & $04(07.1)$ \\
Obesity & $06(10.7)$ \\
Hypertension & $27(48.2)$ \\
Anaemia &
\end{tabular}

The male: female ratio was $2.1: 1$. The minimum age at diagnosis was three months and the maximum age at diagnosis was 16 years 8 months. Median age at onset of symptoms in children with urolithiasis was 8.1 years (IQR 11.1, 4.8). A positive family history of urolithiasis was noted in $12(21.4 \%)$ children, and twelve $(21.4 \%)$ children were born of a consanguineous marriage, four of these having a family history of urolithiasis. The levels of urinary calcium, oxalate, citrate and uric acid were not statistically significantly different in children with and without a family history of urolithiasis. Weak urinary stream was observed in $14(36.8 \%)$ out of 38 children. Abdominal pain along with fever was seen in 14 (25\%) children. Abdominal pain along with haematuria was noted in $13(23.2 \%)$ children. Twenty four $(42.9 \%)$ children had normal growth. All 6 children with hypertension had normal blood pressure at follow up. Phimosis was present in $6(15.8 \%)$ out of 38 children. One of them had meatal stenosis. Four $(7.1 \%)$ children had acute changes in renal function during hospitalisation, which returned to normal after treatment. One child had acute kidney injury (AKI) initially with oliguria, was started on AKI protocol and subsequently serum creatinine level normalised. Microscopic haematuria was observed in 18 children, whereas 17 (30.4\%) children had gross haematuria. Pyuria was found in $9(16 \%)$ children, and urine crystals were found in $5(8.9 \%)$ children. Urine culture positivity was seen in 5 $(55.5 \%)$ of the nine children who had pyuria. Common organisms responsible for urinary tract infection (UTI) were Escherichia coli and Proteus. 
The location, size of the stone and associated findings on imaging studies are shown in Table 2.

Table 2

Location, size and number of stones in children with urolithiasis $(n=56)$

\begin{tabular}{|l|c|}
\hline \multicolumn{1}{|c|}{ Variable } & Number (\%) \\
\hline Kidney & $40(71.5)$ \\
Right & $17(30.3)$ \\
Left & $10(17.9)$ \\
Bilateral & $13(23.2)$ \\
\hline Ureter & $07(12.5)$ \\
Right & $04(07.1)$ \\
Left & $03(05.4)$ \\
\hline Bladder & $04(07.1)$ \\
\hline Kidney + Ureter & $05(08.9)$ \\
\hline Stone size & \\
$<3$ mm & $10(17.9)$ \\
3-10 mm & $34(56.9)$ \\
$>10$ mm & $12(21.4)$ \\
\hline Number of stones & $32(57.1)$ \\
Single & $24(42.9)$ \\
Multiple &
\end{tabular}

Calculi were more common on the right side than the left. The median size of the stone was $6 \mathrm{~mm}$ (IQR 8, 4). The smallest stone size was $2 \mathrm{~mm}$, and the largest stone size was $32 \mathrm{~mm}$. Staghorn calculi were observed in $3(5.4 \%)$ children, and 14 (25\%) children were found to have hydronephrosis/ hydroureter/ hydroureteronephrosis. Haematuria was more commonly noted in large-sized calculi (33.3\% in calculi $>10 \mathrm{~mm}$ and $35.3 \%$ in $3-10 \mathrm{~mm}$ calculi) while it was less common (10\%) among those with smaller stones.

The 24 hour urine metabolic evaluation in children with urolithiasis is shown in Table 3.

Table 3

24 hour urine metabolic evaluation in children with urolithiasis $(N=54)$

\begin{tabular}{|l|c|}
\hline \multicolumn{1}{|c|}{ Variable } & Number (\%) \\
\hline Hypercalciuria & $08(14.8)$ \\
\hline Hyperoxaluria & $20(37.0)$ \\
\hline Hypermagnesuria & $16(29.6)$ \\
\hline Hypocitraturia & $34(63.1)$ \\
\hline Hyperphosphaturia & $02(03.7)$ \\
\hline Hyperuricosuria & $0(0)$ \\
\hline
\end{tabular}

Only 54 children underwent 24 hour urine metabolic evaluation and all of them had at least one metabolic abnormality. The 8 children with hypercalciuria had normal serum calcium levels and the 2 children with hyperphosphaturia had normal serum phosphorus levels. None of the children had hyperuricosuria in the present study.

UTI was noted in $6(10.7 \%)$ children and anatomical defects in $9(16.1 \%)$ children with urolithiasis. Of the 9 children with anatomical defects, 6 had phimosis, 2 had vesico-ureteric reflux (VUR) and one had bifid ureter.

Treatment modalities used in the children with urolithiasis are shown in Table 4.

\section{Table 4}

Treatment modalities in children with urolithiasis $(n=56)$

\begin{tabular}{|c|c|}
\hline Treatment & No. $(\%)$ \\
\hline Conservative & $38(67.9)$ \\
\hline Surgical & $18(32.1)$ \\
\hline Endoscopic & 07 \\
\hline ureteroscopy & 05 \\
\hline Percutaneous nephrolithotomy & 03 \\
\hline Percutaneous cystolithotripsy & 01 \\
\hline Ureterolithotomy & 01 \\
\hline Pyelolithotomy & 01 \\
\hline Ureterolithotripsy & \\
\hline
\end{tabular}

The smallest size of stone surgically removed in children with urolithiasis was $4 \mathrm{~mm}$, and it was a ureteric calculus removed by an endoscopic method. The largest size of stone surgically removed was $32 \mathrm{~mm}$, and it was removed by pyelolithotomy from the kidney.

Stone analysis was done in 8 children of whom two had calcium oxalate and 2 had calcium oxalate with uric acid. Calcium oxalate with ammonium urate, calcium phosphate, calcium phosphate with uric acid and a combination of calcium oxalate, calcium phosphate with uric acid was observed in one each.

In the present study, 35 (77.8\%) out of 45 children were asymptomatic at follow up. In children with recurrence, four children were asymptomatic but three had pain in abdomen at follow up. Blood pressure was observed to be standard in all children with urolithiasis at follow up. Out of the 45 children, $10(22.2 \%)$ had persisting calculi, 7 $(15.5 \%)$ had a recurrence, and in the remaining 28 $(62.2 \%)$ no recurrence was observed.

\section{Discussion}

The composition, incidence and clinical features of urolithiasis in children vary from place to place and from decade to decade ${ }^{6}$. Metabolic disorders are currently the most frequent causes of calculi in European countries ${ }^{7}$. The common causes of urolithiasis among children are metabolic in 50\%, structural abnormalities in $32 \%$ and infections in $4 \%$ cases $^{8}$. Median age at onset of symptoms in children with urolithiasis was 8.1 years. The study group had 38 boys and 18 girls. Male: female ratio was 2.1:1. Similar observations were noted in a study by Rizvi et al. ${ }^{9}$ with a median age at onset of symptoms in children with urolithiasis of seven years and a $\mathrm{M}$ : $\mathrm{F}$ ratio of $2 \cdot 2: 1^{10}$. Male 
predominance was observed in several similar studies $^{9,11,12}$.

In the present study, a positive family history of urolithiasis was found in $12(21.4 \%)$ children, and $12(21.4 \%)$ children were born out of consanguineous marriage. Naseri et al. found a positive family history in $63 \%$ of children with renal calculi in a prospective study ${ }^{13}$. Vandervoort et al. also found a positive family history in $50 \%$ of children with urolithiasis in a retrospective study ${ }^{1}$.

In the present study, in children with urolithiasis the common presenting symptoms were abdominal pain $(87.5 \%)$, fever $(30.4 \%)$ and haematuria (30.4\%). Similar observations were found in studies done by Akram Alaya et al. and Abhishek et $a .^{12,14}$. In the present study, microscopic haematuria was observed in $32 \%$ children, gross haematuria in $30 \%$, pyuria in $16 \%$, and urine crystals in $9 \%$. In a study by Rizvi et al(9)., haematuria was detected in $36 \%$ children with urolithiasis, pyuria in $32 \%$ and calcium oxalate crystals in $54 \%$.

Metabolic variations have been defined in 33-93\% of children with urinary calculi $1^{1,13,15-19}$. In our study, we found at least one metabolic abnormality in each of the 54 children assessed. Hypocitraturia, hyperoxaluria and hypermagnesuria were the common metabolic disorders found in our study. A number of studies have shown the presence of hypercalciuria in $72-88 \%$ of children with urinary calculi $^{6,20-24}$. In our study hypercalciuria was found in only $14.8 \%$.

In our study, $71.5 \%$ of urinary calculi were located in the upper urinary tract. This is similar to the findings of other recent studies $1,5,18,24$. In our study the calculi were analysed in only $14 \%$ children but among them calcium stones were the most frequent. This was similar to the findings of Rellum et al. ${ }^{16}$.

In this study, conservative therapy was given in $68 \%$ of children. Citrate therapy has been shown to decrease the recurrence of new stones and reduction of stone formation in children with hypocitraturia $^{25}$. However, thiazide diuretic remains the therapy of choice for patients with calcium stones, reducing their formation ${ }^{28}$. Surgery was carried out in $32 \%$ children in our study. The surgical methods used included endoscopic removal with ureteroscopy, percutaneous nephrolithotomy, percutaneous cystolithotripsy, ureterolithotomy, pyelolithotomy and ureterolithotripsy. Out of the 45 children studied on follow up, $10(22.2 \%)$ had persisting calculi and 7 $(15.5 \%)$ had a recurrence.
The study has some limitations. It was conducted in a single setting and the sample size was limited. Since the presentation of paediatric patients with renal calculi differs from the classical renal colic seen in adults, children presenting with flank pain or chronic recurrent abdominal pain should be investigated for the possibility of urinary calculi. Since hypocitraturia and hyperoxaluria are common causes of paediatric urolithiasis, a urinary metabolic analysis should be carried out in children with urinary stones.

\section{Conclusions}

Abdominal pain was the presenting symptom in $87.5 \%$ cases. Hypocitraturia was observed in $63.1 \%$ cases. Majority $(71.5 \%)$ of calculi were in the kidney. There were recurrent calculi in $15.5 \%$.

\section{References}

1. VanDervoort K, Wiesen J, Frank R, Vento $\mathrm{S}$, Crosby $\mathrm{V}$, Chandra $\mathrm{M}$, et al. Urolithiasis in paediatric patients: a single centre study of incidence, clinical presentation and outcome. The Journal of Urology 2007; 177(6):2300-5.

https://doi.org/10.1016/j.juro.2007.02.002 PMid: 17509344

2. Sas DJ, Hulsey TC, Shatat IF, Orak JK. Increasing incidence of kidney stones in children evaluated in the emergency department. Journal of Pediatrics 2010;157(1):132-7. https://doi.org/10.1016/j.jpeds.2010.02.00 4

PMid: 20362300

3. Dwyer ME, Krambeck AE, Bergstralh EJ, Milliner DS, Lieske JC, Rule AD. Temporal trends in incidence of kidney stones among children: a 25-year population based study. The Journal of Urology 2012; 188(1):247-52.

https://doi.org/10.1016/j.juro.2012.03.021 PMid: 22595060 PMCid: PMC3482509

4. Joshi VS, Parekh BB, Joshi MJ, Vaidya AD. Inhibition of the growth of urinary calcium hydrogen phosphate dihydrate crystals with aqueous extracts of Tribulus terrestris and Bergenia ligulata. Urological Research 2005; 33(2):80-6. https://doi.org/10.1007/s00240-004-04506

PMid: 15791467

5. Spivacow FR, Negri AL, del Valle EE, Calvino I, Fradinger E, Zanchetta JR. Metabolic risk factors in children with 
kidney stone disease. Pediatric

Nephrology 2008; 23(7):1129-33.

https://doi.org/10.1007/s00467-008-0769-

2

PMid: 18324422

6. Ali SH, Rifat UN. Etiological and clinical patterns of childhood urolithiasis in Iraq. Pediatric Nephrology 2005; 20(10):14537.

https://doi.org/10.1007/s00467-005-19710

PMid: 16010596

7. Polinsky MS, Kaiser BA, Baluarte HJ. Urolithiasis in childhood. Pediatric Clinics of North America 1987; 34(3):683710.

https://doi.org/10.1016/S00313955(16)36262-9

8. Milliner DS, Murphy ME. Urolithiasis in paediatric patients. Mayo Clinic Proceedings 1993; 68(3):241-8. https://doi.org/10.1016/S00256196(12)60043-3

9. Rizvi SA, Sultan S, Zafar MN, Ahmed B, Faiq SM, Hossain KZ, et al. Evaluation of children with urolithiasis. Indian Journal of Urology 2007; 23(4):420-7. https://doi.org/10.4103/0970-1591.36717 PMid: 19718299 PMCid: PMC2721575

10. Amancio L, Fedrizzi M, Bresolin NL, Penido MG. Pediatric urolithiasis: experience at a tertiary care pediatric hospital. Jornal Brasileiro De Nefrologia 2016; 38(1):90-8.

https://doi.org/10.5935/0101-

2800.20160014

PMid: 27049370

11. Oner A, Demircin $G$, Ipekcioglu $H$, Bulbul M, Ecin N. Etiological and clinical patterns of urolithiasis in Turkish children. European Urology 1997; 31(4):453-8. https://doi.org/10.1159/000474506 PMid: 9187907

12. Alaya A, Belgith M, Hammadi S, Nouri A, Najjar MF. Kidney stones in children and teenagers in the central coast region of Tunisia. Iranian Journal of Pediatrics 2012; 22(3):290-6.

PMid: 23400694 PMCid: PMC3564081

13. Naseri M, Varasteh AR, Alamdaran SA. Metabolic factors associated with urinary calculi in children. Iranian Journal of Kidney Diseases 2010; 4(1):32-8.

PMid: 20081302

14. Abhishek, Kumar J, Mandhani A, Srivastava A, Kapoor R, Ansari MS. Pediatric urolithiasis: experience from a tertiary referral center. Journal of Pediatric Urology 2013; 9(6 Pt A):82530.

https://doi.org/10.1016/j.jpurol.2012.11.00 3

PMid: 23348148

15. Penido MG, Srivastava $\mathrm{T}$, Alon US. Pediatric primary urolithiasis: 12-year experience at a Midwestern Children's Hospital. The Journal of Urology 2013;189(4):1493-7.

https://doi.org/10.1016/j.juro.2012.11.107 PMid: 23201378

16. Rellum DM, Feitz WF, van Herwaarden AE, Schreuder MF. Pediatric urolithiasis in a non-endemic country: a single center experience from The Netherlands. Journal of Pediatric Urology 2014; 10(1):155-61. https://doi.org/10.1016/j.jpurol.2013.07.01 9

PMid: 23981680

17. Alpay H, Ozen A, Gokce I, Biyikli N. Clinical and metabolic features of urolithiasis and microlithiasis in children. Pediatric Nephrology 2009; 24(11):22039. https://doi.org/10.1007/s00467-009-12319

PMid: 19603196

18. Pietrow PK, Pope JCt, Adams MC, Shyr Y, Brock JW, 3rd. Clinical outcome of pediatric stone disease. The Journal of Urology 2002; 167(2 Pt 1):670-3.

https://doi.org/10.1016/S00225347(01)69121-3

19. Alemzadeh-Ansari MH, Valavi E, Ahmadzadeh A. Predisposing factors for infantile urinary calculus in south-west of Iran. Iranian Journal of Kidney Diseases 2014; 8(1):53-7.

PMid: 24413722

20. Safaei Asl A, Maleknejad S. Pediatric urolithiasis: an experience of a single center. Iranian Journal of Kidney Diseases 2011; 5(5):309-13. PMid: 21876306 
21. Kit LC, Filler G, Pike J, Leonard MP. Pediatric urolithiasis: experience at a tertiary care pediatric hospital. Canadian Urological Association Journal 2008; 2(4):381-6.

https://doi.org/10.5489/cuaj.804

PMid: 18781210 PMCid: PMC2532545

22. Bush NC, Xu L, Brown BJ, Holzer MS, Gingrich A, Schuler B, et al. Hospitalizations for paediatric stone disease in United States, 2002-2007. The Journal of Urology 2010; 183(3):1151-6. https://doi.org/10.1016/j.juro.2009.11.057 PMid: 20096871

23. Copelovitch L. Urolithiasis in children: medical approach. Pediatric Clinics of North America 2012; 59(4):881-96. https://doi.org/10.1016/j.pcl.2012.05.009 PMid: 22857835 PMCid: PMC3426770

24. Milosevic D, Batinic D, Turudic D, Batinic D, Topalovic-Grkovic M, Gradiski IP. Demographic characteristics and metabolic risk factors in Croatian children with urolithiasis. European Journal of Pediatrics 2014; 173(3):353-9. https://doi.org/10.1007/s00431-013-21656

PMid: 24096520
25. Sarica K, Erturhan S, Yurtseven C, Yagci F. Effect of potassium citrate therapy on stone recurrence and regrowth after extracorporeal shockwave lithotripsy in children. Journal of Endourology 2006; 20(11):875-9. https://doi.org/10.1089/end.2006.20.875 PMid: 17144854

26. Xu H, Zisman AL, Coe FL, Worcester EM. Kidney stones: an update on current pharmacological management and future directions. Expert Opinion on Pharmacotherapy 2013; 14(4):435-47. https://doi.org/10.1517/14656566.2013.77 5250

PMid: 23438422 PMCid: PMC3772648 